\title{
Cost-Effectiveness of Canagliflozin Added to Standard of Care for Treating Diabetic Kidney Disease (DKD) in Patients with Type 2 Diabetes Mellitus (T2DM) in England: Estimates Using the CREDEM-DKD Model
}

\author{
Michael Willis · Andreas Nilsson · Klas Kellerborg • Philip Ball • \\ Rupert Roe $\cdot$ Shana Traina $\cdot$ Rebecca Beale $\cdot$ Isabelle Newell
}

Received: October 8, 2020 / Accepted: November 6, 2020 / Published online: December 2, 2020

(C) The Author(s) 2020

\section{ABSTRACT}

Introduction: On the basis of reductions in diabetic kidney disease (DKD) progression and major adverse cardiovascular events observed in the landmark CREDENCE trial, canagliflozin $100 \mathrm{mg}$ received an extension to its EU marketing authorisation in July 2020 to include the treatment of DKD in people with type 2 diabetes mellitus (T2DM) making it the first pharmacological therapy to receive regulatory authorisation for treatment of DKD since the RENAAL and IDNT trials in nearly 20 years. Efficient allocation of limited healthcare resources requires evaluation not only of clinical safety and efficacy but also economic

Electronic supplementary material The online version of this article (https://doi.org/10.1007/s13300020-00968-x) contains supplementary material, which is available to authorized users.

M. Willis $(\varangle) \cdot$ A. Nilsson · K. Kellerborg The Swedish Institute for Health Economics, Lund, Sweden

e-mail: mw@ihe.se

P. Ball

Mundibiopharma Limited, Cambridge, UK

R. Roe

Napp Pharmaceuticals Limited, Cambridge, UK

S. Traina

Janssen Global Services, LLC, Raritan, NJ, USA

R. Beale $\cdot$ I. Newell

Costello Medical Consulting Limited, London, UK consequences. The study aim was to estimate the cost-effectiveness of canagliflozin when added to current standard of care (SoC) versus SoC alone from the perspective of the NHS in England.

Methods: A microsimulation model was developed using patient-level data from CREDENCE, including risk equations for the key clinical outcomes of start of dialysis, hospitalisation for heart failure, nonfatal myocardial infarction, nonfatal stroke, and all-cause mortality. DKD progression was modelled using estimated glomerular filtration rate and urinary albuminto-creatinine ratio evolution equations. Risk for kidney transplant was sourced from UK-specific sources given the near absence of events in CREDENCE. Patient characteristics and treatment effects were sourced from CREDENCE. Unit costs (£2019) and disutility weights were sourced from the literature and discounted at 3.5\% annually. The time horizon was 10 years in the base case, and sensitivity analysis was performed. Results: Canagliflozin was associated with sizable gains in life-years and quality-adjusted lifeyear (QALYs) over 10 years, with gains increasing with simulation duration. Cost offsets associated with reductions in cardiovascular and renal complications were sufficient to achieve overall net cost savings. The findings were generally confirmed in the sensitivity analyses.

Conclusion: Model results suggest that adding canagliflozin $100 \mathrm{mg}$ to SoC can improve patient outcomes while reducing overall net costs from the NHS perspective in England. 
Trial Registration: ClinicalTrials.gov identifier, NCT02065791.

Keywords: Albuminuria; Canagliflozin; Chronic kidney disease (CKD); Costeffectiveness; CREDENCE; Diabetes; Diabetic kidney disease (DKD); Diabetic nephropathy; Dialysis

\section{Key Summary Points}

Why carry out this study?

The CREDENCE study, which compared canagliflozin $100 \mathrm{mg}+$ standard of care (SoC) treatment versus SoC treatment alone, was the first study to show improved patient outcomes in individuals with diabetic kidney disease (DKD) since current SoC was established almost 20 years ago.

While the observed improvements in renal and cardiovascular outcomes are likely to improve well-being in these patients, it remains to be seen whether the additional costs of adding canagliflozin $100 \mathrm{mg}$ to SoC provides good value for money in England (and elsewhere).

This study addressed the question of value for money by leveraging a new microsimulation model (CREDEM-DKD) to estimate the incremental costeffectiveness ratio (ICER) for individuals with DKD from the NHS perspective in England.

\section{What was learned from the study?}

Extrapolating the renal and cardiovascular benefits demonstrated in the CREDENCE trial to a 10-year time horizon was associated with considerable gains in health and lower overall costs, a "winwin" situation versus SoC alone. Savings in dialysis and transplantation were the largest cost drivers.

The benefits, but also decision-making uncertainty, were found to increase with longer time horizons.

\section{DIGITAL FEATURES}

This article is published with digital features, including a summary slide, to facilitate understanding of the article. To view digital features for this article go to https://doi.org/10.6084/ m9.figshare.13193786.

\section{INTRODUCTION}

Chronic kidney disease (CKD) costs the National Health System (NHS) as much as $£ 1.4$ billion per year in the United Kingdom (UK) [1], and the most common cause is diabetes [2]. The impact of CKD on health-related quality of life is also substantial, especially for severe late stage complications requiring treatment with dialysis or kidney transplantation [3, 4]. Diabetic kidney disease (DKD) is a distinct subtype of CKD, defined by the comorbid presence of both diabetes mellitus and CKD, in the absence of any other apparent CKD aetiology [5]. In approximately half of patients with type 2 diabetes mellitus (T2DM) developing renal impairment, measurable levels of albuminuria can be detected prior to decline of estimated glomerular filtration rate (eGFR) below $60 \mathrm{~mL} / \mathrm{min} / 1.73 \mathrm{~m}^{2}$; therefore albuminuria is used clinically as an early marker of nephropathy risk in T2DM [6]. In the UK, approximately $40 \%$ of patients with prevalent T2DM are estimated to have moderately-severely decreased eGFR and/or moderately-severely increased albuminuria [7]. Both elevated albuminuria and reduced GFR are independently associated with significantly increased risk of cardiovascular mortality, as well as other complications such as amputation $[8,9]$. As such, only a small proportion of patients with $\mathrm{CKD} / \mathrm{DKD}$ typically reach end-stage renal disease (ESRD), with the majority of patients dying from other causes before ESRD is reached [10]. However, the extremely high healthcare costs associated with ESRD management account for the majority of the CKD/DKD costs to the NHS, despite the relatively small number of patients that require dialysis or transplant.

The Canagliflozin and Renal Endpoints in Diabetes with Established Nephropathy Clinical 
Evaluation (CREDENCE) study [11] was the first dedicated renal outcomes study to report results for a sodium-glucose co-transporter 2 (SGLT2) inhibitor in individuals with DKD, and the first study to show improved patient outcomes in this patient population since current standard of care (SoC) was established almost 20 years ago $[12,13]$. In addition to current SoC, including maximally tolerated dose of a renin-angiotensin-aldosterone system (RAAS) inhibitor, canagliflozin $100 \mathrm{mg}$ reduced the risk of the primary composite endpoint (doubling of serum creatinine [DoSCr], ESKD, or renal or cardiovascular [CV] death) by $30 \%$ $(p=0.00001)$ versus SoC alone [11]. Substantial risk reductions were also observed for several secondary endpoints, including a composite of $\mathrm{CV}$ death or hospitalisation for heart failure (HHF) by $31 \% \quad(p<0.001)$, 3-point major adverse cardiovascular events (MACE: CV death, nonfatal myocardial infarction [MI], or nonfatal stroke) by $20 \%(p=0.01)$, and HHF alone by $39 \%(p<0.001)$ [11]. On the basis of these results, canagliflozin $100 \mathrm{mg}$ received an indication extension for the treatment of DKD in patients with insufficiently controlled T2DM in Europe in July 2020 [14]. Management of renal and cardiovascular morbidity and mortality are now considered integral parts of the treatment of T2DM, and as such the label includes these treatment goals within the overall T2DM therapeutic indication of canagliflozin, rather than as distinct labelled indications.

Efficient allocation of scarce healthcare resources requires not only that treatments demonstrate clinical safety and efficacy but that they provide good "value for money" (i.e. are cost-effective) as well. For a good review of costeffectiveness methodology used by economic stakeholders, see Drummond et al. [15]. For chronic and progressive diseases such as DKD, economic evidence is routinely generated using economic modeling methods that extrapolate trial outcomes to longer time horizons (thus, estimating the full long-term costs and benefits of intervention). When properly constructed and validated, economic models can provide a more complete accounting of the relevant cost and health trade-offs of alternative treatment approaches than economic analyses based on single clinical trials alone [16-18]. An economic model was developed using patient-level data from the CREDENCE trial to support estimation of the cost-effectiveness of canagliflozin in this new indication [19].

The objective of this study was to estimate the cost-effectiveness of canagliflozin $100 \mathrm{mg}+$ SoC versus SoC alone in the treatment of individuals with T2DM and DKD from the perspective of the NHS in England.

\section{METHODS}

\section{Model Summary}

The CREDENCE Economic Model of DKD (CREDEM-DKD) model uses the microsimulation approach to estimate cost-effectiveness of treatment interventions. It is implemented with discrete event simulation (DES) methods, which are well suited to situations where there are competing clinical events and accelerating risks (e.g. of reaching ESRD), and relatively long-term "time-to-event" data are available to enable estimation of risk prediction equations [11, 20], as is the case with DKD and the CREDENCE trial. First- and second-order uncertainty are captured explicitly, and the time horizon and discount rates are user-definable. CREDEM-DKD is implemented in Microsoft ${ }^{\circledR}$ Excel (Microsoft Corporation, Redmond, Washington, USA) and Visual Basic for Applications. CREDEM-DKD was designed, constructed, and populated with patient-level data from CREDENCE in accordance with the recommendations of the International Society of Pharmacoeconomic and Outcomes Research-Society of Medical Decision Making (ISPOR-SMDM) Modeling Good Research Practices Task Force-2 [21]. A pragmatic and parsimonious design was chosen to preserve the information in the CREDENCE trial without creating unnecessary complexity or introducing undue risk for overfitting of the model to the CREDENCE study. This approach included limiting time-varying covariates in the risk equations to cases where ignoring a temporal relationship could not reasonably be avoided (e.g. age) and omitting treatment 
intensification algorithms. The model structure is presented in Fig. 1.

The model is described in detail elsewhere [19]. Briefly, though, simulated patients are characterised at baseline, and at each time point thereafter by a DKD health state based on National Kidney Foundation-Kidney Disease Outcomes Quality Initiative (NKF-KDOQI) stages $(1,2,3 \mathrm{~A}, 3 \mathrm{~B}, 4$, and 5 prior to dialysis), or a "receiving dialysis" or "post renal transplant" health state. Each of these eight renal health states are mutually exclusive $[22,23]$. The renal health states are supplemented with additional health states representing history of MI, stroke, and/or heart failure (HF); and by age, smoking status, and projected eGFR and urine albuminto-creatinine ratio (UACR) biomarker values. The hypothetical patients experience DKD progression in terms of eGFR decline and UACR increase, based on linear mixed model regression equations from the CREDENCE trial [11] or the occurrence of dialysis start or kidney transplant [24]. Start of maintenance dialysis and/or kidney transplantation can optionally be initiated automatically at a user-defined eGFR threshold. The patients also face risks of allcause mortality (ACM), nonfatal MI, nonfatal stroke, and HHF, all based on parsimonious

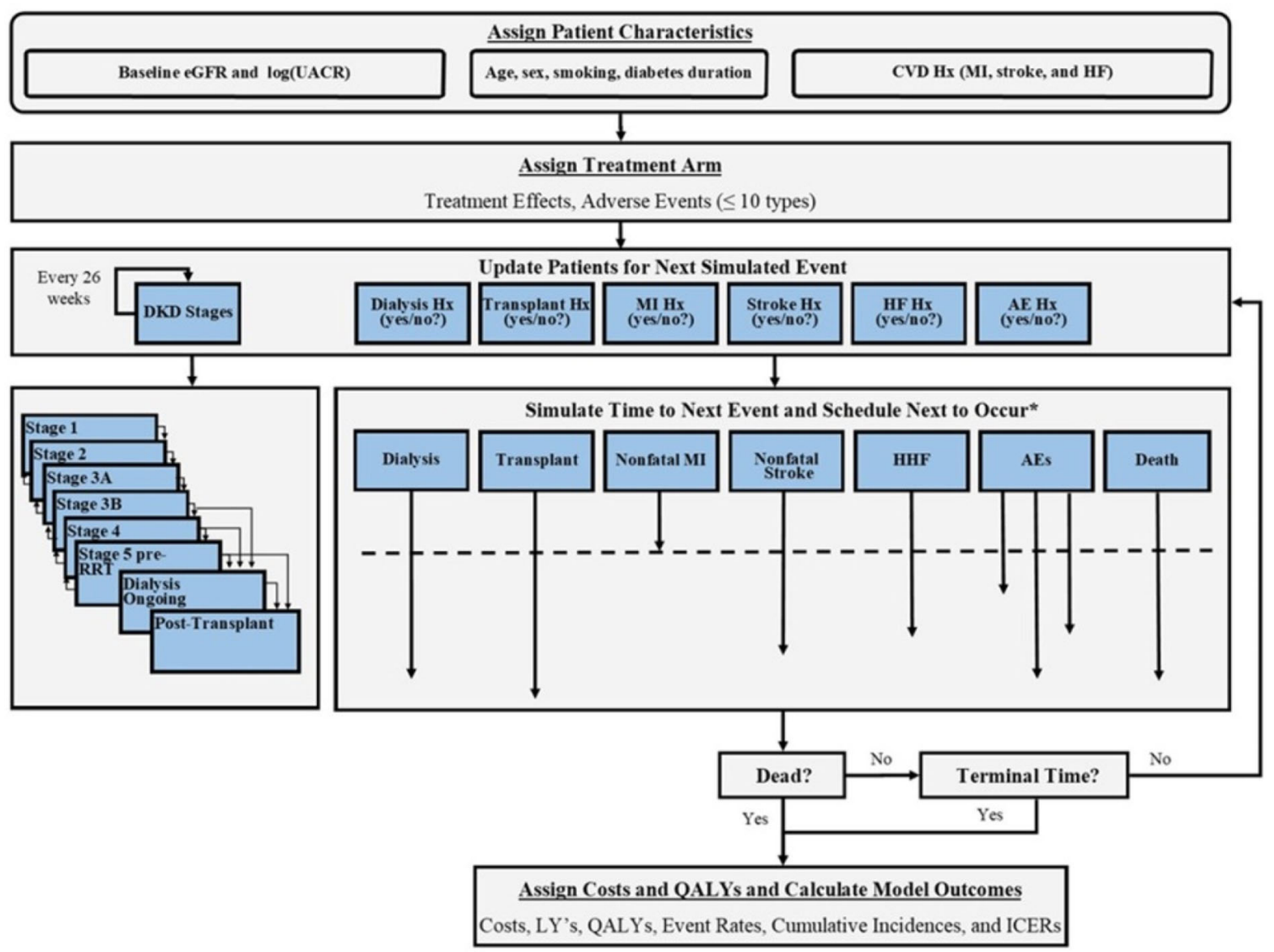

Fig. 1 CREDEM-DKD model structure. *Optionally, doubling of serum creatinine can also be simulated. AE adverse event, CVD cardiovascular disease, CREDEMDKD CREDENCE Economic Model of DKD, CREDENCE Canagliflozin and Renal Endpoints in Diabetes with Established Nephropathy Clinical Evaluation, DoSCr doubling of serum creatinine, eGFR estimated glomerular filtration rate, HF heart failure, HHF hospitalization for heart failure, Hx history, ICER incremental cost-effectiveness ratio, MI myocardial infarction, LY life-year, QALY quality-adjusted life-year, RRT renal replacement therapy, UACR urine albumin-to-creatinine ratio 
parametric time to event risk equations (see Willis et al. [19]). CV can be assigned as cause of death using a logistic regression equation estimated with patient-level CREDENCE data. Treatment can affect eGFR and UACR biomarkers as well as directly modify the risk for dialysis, CV events, and ACM. AEs are defined by an event rate, periodicity (e.g. one-time, repeated, or permanent), duration (e.g. 1 week), and a cost and quality-adjusted life-year (QALY) disutility weight. The user can optionally set a maximum duration after which treatment effects of canagliflozin versus SoC diminish, either immediately with reversion to SoC or linear waning over a user-defined time horizon until the hazard ratios (HRs) between treatment arms return to 1.0 .

CREDEM-DKD was validated in accordance with the recommendations of the ISPOR-SMDM Modeling Good Research Practices Task Force-2 [21], which consisted of model verification (i.e. 'stress testing'), internal validation (i.e. replicating the CREDENCE study results), and limited external validation based on replicating results of the subgroup of CANagliflozin cardioVascular Assessment Study (CANVAS) Program [25] subjects that met CREDENCE study recruitment criteria. External validation will be reassessed when other renal outcomes trials report out. Validation is summarised in an Assessment of the Validation Status of HealthEconomic Decision Models evaluation (AdViSHE) [26] (see electronic supplementary material [ESM] 2).

\section{Input Data}

Baseline patient characteristics were sourced from CREDENCE $[11,20]$ and are presented in Table 1. Treatment effects for the canagliflozin $100 \mathrm{mg}+$ SoC arm were also sourced from CREDENCE $[11,20]$ and the details are presented in ESM Table 1. Between-arm separation in the Kaplan-Meier plots for dialysis, stroke, and mortality first occurred visually after 1 year; so to ensure a conservative approach, treatment effects for these endpoints were not applied during the first year. SoC alone is associated with clinical progression defined by the risk
Table 1 Baseline patient characteristics

\begin{tabular}{|c|c|c|c|}
\hline Risk factors & Mean & $\begin{array}{l}\text { Standard } \\
\text { deviation }\end{array}$ & Source \\
\hline Age & 63.0 & 9.2 & $\begin{array}{l}\text { Perkovic } \\
\text { et al. }[11]\end{array}$ \\
\hline Diabetes duration & 15.8 & 8.6 & $\begin{array}{l}\text { Perkovic } \\
\text { et al. }[11]\end{array}$ \\
\hline Female (\%) & 33.9 & 0.5 & $\begin{array}{l}\text { Perkovic } \\
\text { et al. }[11]\end{array}$ \\
\hline eGFR & 56.2 & 18.2 & $\begin{array}{l}\text { Perkovic } \\
\text { et al. }[11]\end{array}$ \\
\hline $\operatorname{Ln}(\mathrm{UACR})$ & 6.8 & 1.0 & $\begin{array}{l}\text { Perkovic } \\
\text { et al. }[11]\end{array}$ \\
\hline Smoking (\%) & 14.5 & 0.4 & $\begin{array}{l}\text { Perkovic } \\
\text { et al. }[11]\end{array}$ \\
\hline History of MI (\%) & 10.0 & 0.3 & $\begin{array}{l}\text { Mahaffey } \\
\text { et al. }[20]\end{array}$ \\
\hline $\begin{array}{l}\text { History of stroke } \\
(\%)\end{array}$ & 10.4 & 0.3 & $\begin{array}{l}\text { Mahaffey } \\
\text { et al. }[20]\end{array}$ \\
\hline $\begin{array}{l}\text { History of heart } \\
\text { failure (\%) }\end{array}$ & 14.8 & 0.4 & $\begin{array}{l}\text { Perkovic } \\
\text { et al. }[11]\end{array}$ \\
\hline
\end{tabular}

eGFR estimated glomerular filtration rate, $M I$ myocardial infarction, $U A C R$ urine albumin-to-creatinine ratio

prediction equations in CREDEM-DKD, which are based on the placebo arm in CREDENCE. AEs were included only for the canagliflozin arm (loaded as between-arm difference in CREDENCE) and consist of urinary tract infection, genital mycotic infection, diabetic ketoacidosis, and lower extremity amputation (LEA). The event rates are presented in ESM Table 1. Canagliflozin was discontinued when dialysis is started, kidney transplant occurs, or diabetic ketoacidosis or LEA is simulated to occur, and affected hypothetical patients were reverted to SoC treatment. The price of canagliflozin $100 \mathrm{mg}$ was set at $£ 476.93$ annually, which corresponds to $100 \%$ patient compliance at UK list price [27]. The price of SoC was calculated on the basis of use of background therapy in CREDENCE, separately by arm $(£ 259.40$ 
annually for canagliflozin and $£ 259.18$ annually for the SoC alone arm). (See ESM Table 2 for description of SoC unit costs).

The default risk equations were used to model the risks of starting dialysis, $\mathrm{CV}$ events, and death. However, as a result of the short follow-up period in the CREDENCE trial, the event rates for initiation of dialysis or renal transplant were relatively low, with the majority of ESRD events defined via a persistent eGFR of below $15 \mathrm{~mL} / \mathrm{min} / 1.73 \mathrm{~m}^{2}$. To enhance realism by overriding scenarios in which hypothetical patients could reach implausibly low eGFR without starting RRT, a minimum eGFR threshold of $6 \mathrm{~mL} / \mathrm{min} / 1.73 \mathrm{~m}^{2}$ was set, at which all hypothetical patients would immediately be assigned to start dialysis. The threshold of $6 \mathrm{~mL} / \mathrm{min} / 1.73 \mathrm{~m}^{2}$ was selected conservatively in line with both clinical guidance on initiation of dialysis [28] and actual retrospective UK data showing that the mean eGFR at start of RRT is $7.4 \mathrm{~mL} / \mathrm{min} / 1.73 \mathrm{~m}^{2}$ [29]. For patients simulated to reach stage $5 \mathrm{DKD}$ or to start dialysis, a $7.5 \%$ annual probability of receiving a kidney transplant was assumed [24].

Unit costs (inflated to £2019) and QALY weights were sourced from the literature (Table 2). The widely used UKPDS cost estimates [30] were used for individual CV complications. Kerr and colleagues [1] was used for cost of dialysis and kidney transplant. Costs for DKD stages were sourced from a previous National Institute for Health and Care Excellence (NICE) Single Technology Appraisal [24]. Health-related quality of life data were not collected in CREDENCE, and utility values used to inform kidney disease stages in the aforementioned appraisal [24] were critiqued for their lack of generalisability to the UK. A targeted literature review was therefore conducted to identify utilities to inform the DKD stages 1-5 and RRT health states that would be reflective of UK patients (see ESM 1 for description of the search strategy). Jesky and colleagues [31] was selected as the most relevant and valid source of QALY weights from a UK perspective for DKD stages $1-5$, whereas Lee and colleagues [32] was selected as the most relevant and valid source for dialysis and kidney transplant. Costs and QALYs were discounted at 3.5\% annually. All analyses consisted of simulating 500 cohorts of 500 hypothetical patients and the time horizon in the base case was 10 years (capturing much of the economic and health consequences of treatment for this patient population but not engendering undue uncertainty by extrapolating too far beyond the duration of the CREDENCE trial).

\section{Sensitivity Analysis}

Eight carefully chosen sensitivity analyses were conducted to evaluate the robustness of model results to changes in essential model parameters and assumptions (see details in Table 3):

- Longer decision-making horizons of 20 years and 40 years (for this patient group, closely reflecting the NICE preferred lifetime horizon) and a shorter time horizon of 5 years

- Waning canagliflozin direct treatment effects (HRs) on renal, CV, and mortality outcomes starting at year 6 (consistent with the longest demonstrated duration of effects in the maximum follow-up of the CANVAS trial $[25,39])$ and continuing linearly to end of simulation

- Including 1st year treatment effects (HRs) for stroke, dialysis, and mortality

- Removal of the assumed eGFR fail-safe floor of $6 \mathrm{~mL} / \mathrm{min} / 1.73 \mathrm{~m}^{2}$, below which dialysis is started (if not already ongoing)

- Assuming same eGFR trajectory for canagliflozin $100 \mathrm{mg}$ and SoC arms

\section{Compliance with Ethics Guidelines}

This article is based on previously conducted studies and does not contain any studies with human participants or animals performed by any of the authors.

\section{RESULTS}

The base case results are presented in Table 3 . The clinical benefits observed for canagliflozin in CREDENCE-including preservation of eGFR, reduction in UACR, and substantial reductions 
Table 2 Unit costs and disutility weights

\begin{tabular}{|c|c|c|c|}
\hline & \multicolumn{2}{|c|}{ Unit costs $(\mathfrak{E})$} & $\begin{array}{l}\text { Utility } \\
\text { weights }\end{array}$ \\
\hline Canagliflozin & \multicolumn{2}{|l|}{476.93} & $\mathrm{~N} / \mathrm{A}$ \\
\hline $\begin{array}{l}\text { SoC in canagliflozin } \\
\text { arm }\end{array}$ & \multicolumn{2}{|l|}{259.40} & N/A \\
\hline SoC in placebo arm & \multicolumn{2}{|l|}{259.18} & N/A \\
\hline Test costs & \multicolumn{2}{|l|}{2.64} & N/A \\
\hline Intercept & \multicolumn{2}{|l|}{$\mathrm{N} / \mathrm{A}$} & $0.785[33]$ \\
\hline Kidney & Event & Annual & \\
\hline DKD stage 1 & 0 & $189[24]$ & $-0.15[31]$ \\
\hline DKD stage 2 & 0 & $189[24]$ & $-0.15[31]$ \\
\hline DKD stage $3 a$ & 0 & $\begin{array}{l}1580 \\
{[24]}\end{array}$ & $-0.20[31]$ \\
\hline DKD stage $3 b$ & 0 & $\begin{array}{l}1580 \\
{[24]}\end{array}$ & $-0.20[31]$ \\
\hline DKD stage 4 & 0 & $\begin{array}{l}3694 \\
{[24]}\end{array}$ & $-0.26[31]$ \\
\hline DKD stage 5 & 0 & $\begin{array}{l}5764 \\
{[24]}\end{array}$ & $-0.27[31]$ \\
\hline Dialysis & 0 & $\begin{array}{c}27,270 \\
{[1]}\end{array}$ & $-0.53[32]$ \\
\hline Transplant & 32,317 & $8519[1]$ & $-0.29[32]$ \\
\hline \multicolumn{4}{|l|}{$\mathrm{CV}$} \\
\hline Nonfatal MI & $\begin{array}{c}6069 \\
{[30]}\end{array}$ & $918[30]$ & $-0.06[33]$ \\
\hline Nonfatal stroke & $\begin{array}{l}6618 \\
{[30]}\end{array}$ & $979[30]$ & $-0.16[33]$ \\
\hline HHF & $\begin{array}{l}1897 \\
{[30]}\end{array}$ & $\begin{array}{l}1601 \\
{[30]}\end{array}$ & $-0.11[33]$ \\
\hline \multicolumn{4}{|l|}{ Adverse events } \\
\hline GMI male & $56[34]$ & - & $\begin{array}{c}-0.0046 \\
{[35]}\end{array}$ \\
\hline GMI female & $52[34]$ & - & $\begin{array}{c}-0.0046 \\
{[35]}\end{array}$ \\
\hline UTI & 99 [34] & - & $\begin{array}{c}-0.0043 \\
{[35]}\end{array}$ \\
\hline
\end{tabular}

Table 2 continued

\begin{tabular}{lccc}
\hline & \multicolumn{2}{c}{ Unit costs $(\mathfrak{E})$} & $\begin{array}{l}\text { Utility } \\
\text { weights }\end{array}$ \\
\hline DKA & 2052 & - & -0.0091 \\
& {$[36]$} & & {$[37]$} \\
LEA & 3808 & 1039 & -0.169 \\
& {$[36]$} & {$[36]$} & {$[33,38]$} \\
\hline
\end{tabular}

$C V$ cardiovascular, $D K A$ diabetic ketoacidosis, $D K D$ diabetic kidney disease, GMI genital mycotic infections, $H H F$ hospitalization for heart failure, $L E A$ lower extremity amputation, $M I$ myocardial infarction, $S o C$ standard of care, UTI urinary tract infection

in the risks of dialysis, CV events, and mortality-confer 0.27 more life-years, 0.28 more QALYs, and cost savings of $£ 4706$ over 10 years for each individual. The cost savings are driven primarily by cost offsets associated with reductions in dialysis (£2754) and progression to DKD stages 4 and 5 ( $£ 2372$ and $£ 2256$, respectively). Canagliflozin was associated with modest cost savings for MI (£45), stroke $(£ 19)$, and HF (£206), but the reduction in event rates was partially offset by increased survival and longer exposure to the risks. Net AE costs were low, given low event rates in CREDENCE and relative balance between study arms. QALY gains were driven primarily by the longer survival for canagliflozin with some benefits sourced from reduced progression of DKD. Progression through the different DKD stages over time are presented in Fig. 2 and cumulative incidence curves for renal and CV events are presented in Fig. 3. Evolution of eGFR over time is presented in ESM Fig. 1.

Model uncertainty was low. Nearly all of the cohort replications fell in quadrant IV, characterised by both lower costs and more QALYs for canagliflozin (Fig. 4), and the likelihood is 96\% that the canagliflozin plus SoC arm costs less than the SoC alone arm (as indicated by the height of the cost-effectiveness acceptability curve at a willingness-to-pay threshold of $£ 0$ for a QALY in Fig. 5). The cost-effectiveness acceptability curve climbs to $99 \%$ at the widely used NICE willingness-to-pay for a QALY of $£ 30,000$. 
Table 3 Economic outcomes for canagliflozin $100 \mathrm{mg}+\mathrm{SoC}$ versus SoC alone over 10 years

\begin{tabular}{|c|c|c|c|}
\hline & Canagliflozin + SoC & SoC & Difference \\
\hline \multicolumn{4}{|l|}{ Treatments } \\
\hline Canagliflozin & 3312 & - & 3312 \\
\hline SoC & 1875 & 1802 & 73 \\
\hline \multicolumn{4}{|l|}{ DKD outcomes } \\
\hline Stage 1 & 0 & 0 & 0 \\
\hline Stage 2 & 243 & 173 & 70 \\
\hline Stage $3 \mathrm{~A}$ & 3562 & 2429 & 1133 \\
\hline Stage 3B & 3792 & 3171 & 621 \\
\hline Stage 4 & 2816 & 5188 & -2372 \\
\hline $\begin{array}{l}\text { Stage } 5 \text { pre- } \\
\text { RRT }\end{array}$ & 138 & 2394 & -2256 \\
\hline Dialysis & 11,311 & 14,065 & -2754 \\
\hline Transplant & 422 & 2673 & -2252 \\
\hline $\begin{array}{l}\text { DKD } \\
\text { subtotal }\end{array}$ & 22,284 & 30,094 & -7810 \\
\hline \multicolumn{4}{|l|}{$\mathrm{CV}$ outcomes } \\
\hline MI & 1258 & 1303 & -45 \\
\hline Stroke & 1237 & 1256 & -19 \\
\hline HHF & 2497 & 2703 & -206 \\
\hline $\mathrm{CV}$ death & 397 & 498 & -101 \\
\hline \multicolumn{4}{|c|}{ Adverse events (incremental for canagliflozin) } \\
\hline UTI & 2 & - & 2 \\
\hline GMI male & 2 & - & 2 \\
\hline GMI female & 1 & - & 1 \\
\hline DKA & 27 & - & 27 \\
\hline LEA & 59 & - & 59 \\
\hline Total costs & 32,950 & 37,656 & -4706 \\
\hline $\begin{array}{l}\text { Time on } \\
\text { treatment } \\
\text { (years) }\end{array}$ & 6.64 & 0.00 & 6.64 \\
\hline Life-years & 7.15 & 6.88 & 0.27 \\
\hline Total QALYs & 3.73 & 3.45 & 0.28 \\
\hline \multicolumn{4}{|c|}{ Sources of disutility } \\
\hline DKD & -1.55 & -1.62 & 0.07 \\
\hline $\mathrm{CV}$ & -0.33 & -0.33 & 0.00 \\
\hline Adverse events & -0.01 & 0.00 & -0.01 \\
\hline Survival & - & - & 0.21 \\
\hline
\end{tabular}

Table 3 continued

\begin{tabular}{|c|c|c|}
\hline Canagliflozin + SoC & SoC & Difference \\
\hline $\begin{array}{l}\text { ICER per } \\
\text { QALY gained }\end{array}$ & & $\begin{array}{c}\text { Canagliflozin } \\
\text { dominates }\end{array}$ \\
\hline \multicolumn{3}{|c|}{$\begin{array}{l}C V \text { cardiovascular, } D K A \text { diabetic ketoacidosis, } D K D \text { chronic kidney } \\
\text { disease, GMI genital mycotic infections, } H H F \text { hospitalization for } \\
\text { heart failure, ICER incremental cost-effectiveness ratio, } L E A \text { lower } \\
\text { extremity amputation, } M I \text { myocardial infarction, } S C C \text { standard of } \\
\text { care, } Q A L Y \text { quality-adjusted life-year, } R R T \text { renal replacement ther- } \\
\text { apy, UTI urinary tract infection }\end{array}$} \\
\hline
\end{tabular}

\section{Sensitivity Analyses}

Results of the sensitivity analyses are summarised in Table 4 and as a tornado diagram in Fig. 6. Increasing the time horizons increased magnitudes of both clinical benefit and cost savings, though substantial mortality in this patient population sets a natural limit. Reducing the time horizon to 5 years was close to finding the break-even point, and associated with an incremental cost-effectiveness ratio (ICER) of $£ 5573$ per QALY gained. Assuming waning of the direct canagliflozin treatment effects on renal, $\mathrm{CV}$, and mortality outcomes starting at year 6 reduced the cost offsets from $£ 4706$ to $£ 4379$ and QALY gains from 0.28 to 0.26 . Including 1st year treatment effects for stroke, dialysis, and mortality had limited impact, with an increase in life-years from 0.27 to 0.32 and an associated decrease in cost savings from $£ 4706$ to $£ 4676$. Removal of the assumed eGFR threshold of $6 \mathrm{~mL} / \mathrm{min} / 1.73 \mathrm{~m}^{2}$ for initiation of dialysis reduced the cost offsets from $£ 4706$ to $£ 3308$ and QALY gains from 0.28 to 0.26 . Assuming no improvement in eGFR for canagliflozin had the largest impact on the results and canagliflozin was associated with higher costs compared with SoC (£2892) with 0.14 QALY gained resulting in an ICER of $£ 20,921$, with decreased costs offsets for DKD stages, as well as dialysis and transplant.

\section{DISCUSSION}

Individuals with T2DM and DKD have substantial unmet medical need as current SoC 


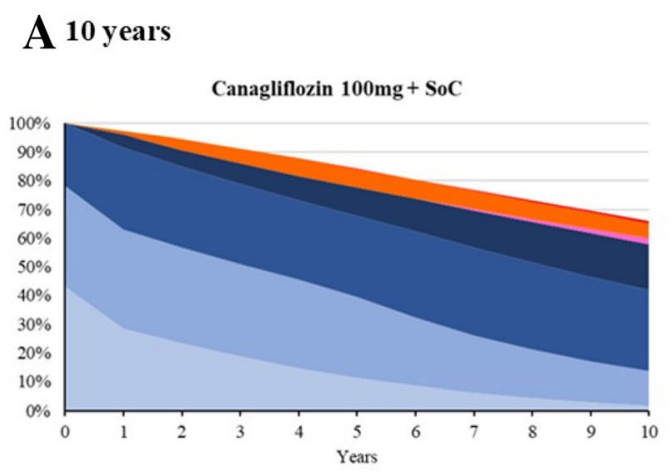

$=2$ = $3 \mathrm{a}=3 \mathrm{~b}=4$ = 5 pre-RRT $=$ Dialysis $=$ Post-Transplant

\section{B 20 years}

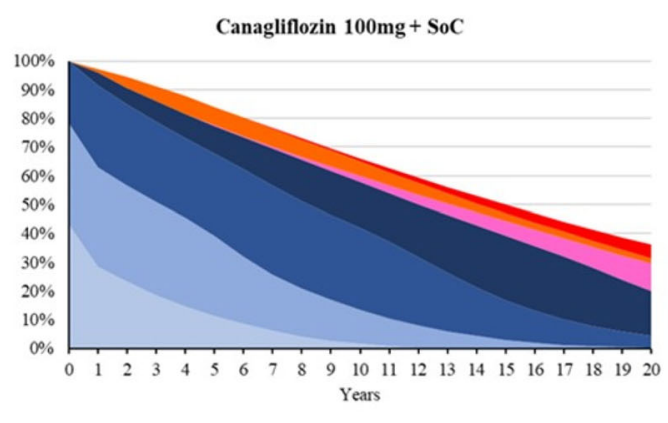

$=2=3 \mathrm{a}=3 \mathrm{~b}=4$ = 4 pre-RRT $=$ Dialysis $=$ Post-Transplant

\section{40 years}

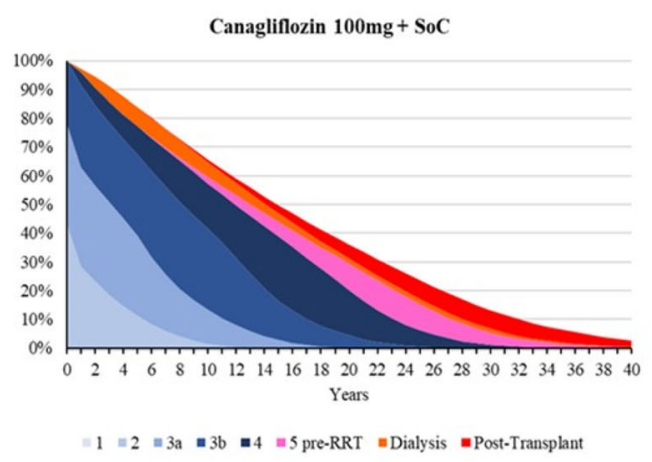

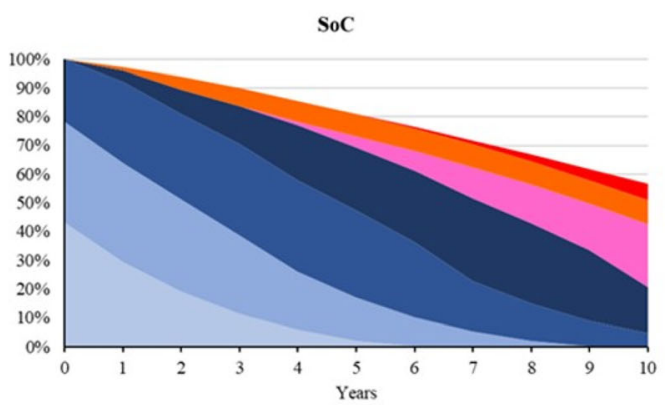

$=2=3 \mathrm{a}=3 \mathrm{~b}=4$ = 5 pre-RRT $=$ Dialysis $=$ Post-Transplant

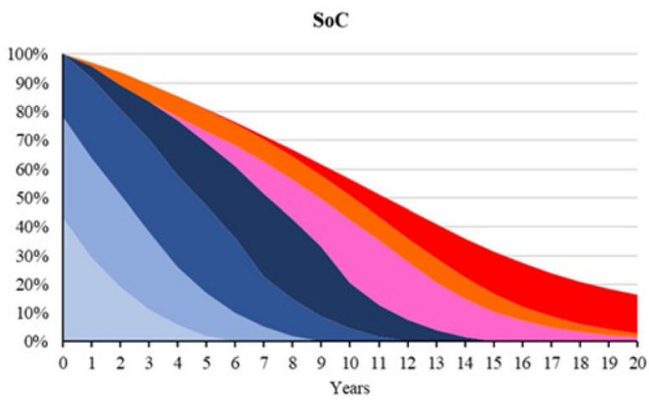

$=2=3 a=3 b=4=5$ pre-RRT $=$ Dialysis $=$ Post-Transplant

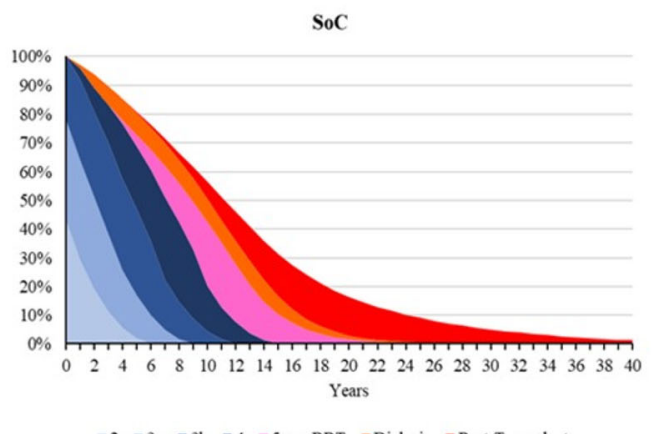

$=2$ - $3 \mathrm{a}=3 \mathrm{~b}=4=5$ pre-RRT $=$ Dialysis $=$ Post-Transplant

Fig. 2 Progression of DKD stages over time. RRT renal replacement therapy

treatments are generally unable to adequately address treatment goals. Furthermore, the impact of people with this condition on healthcare budgets in the UK is disproportional to their population numbers $[1,3,4]$. Economic simulation results extrapolating the CREDENCE study to relevant decision-making time horizons, but otherwise preserving the evidence base in CREDENCE, demonstrated that treatment with canagliflozin has important economic consequences for payer stakeholders in the UK. As an adjunct to current SoC including 
A Start of Dialysis

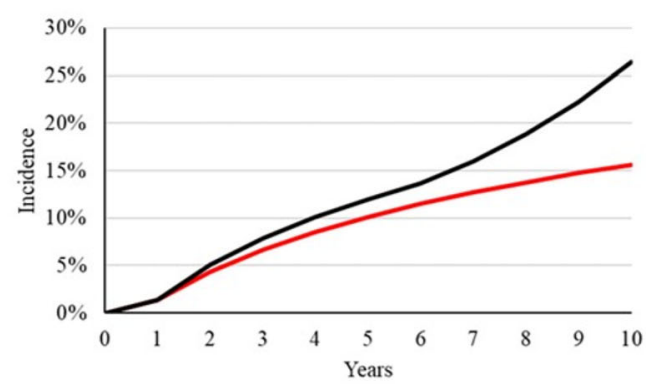

C Nonfatal MI

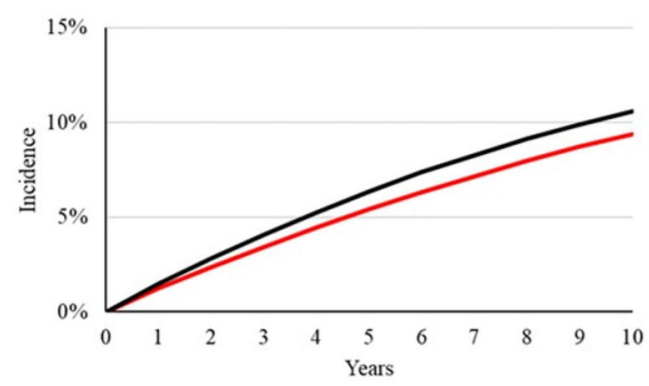

E HHF

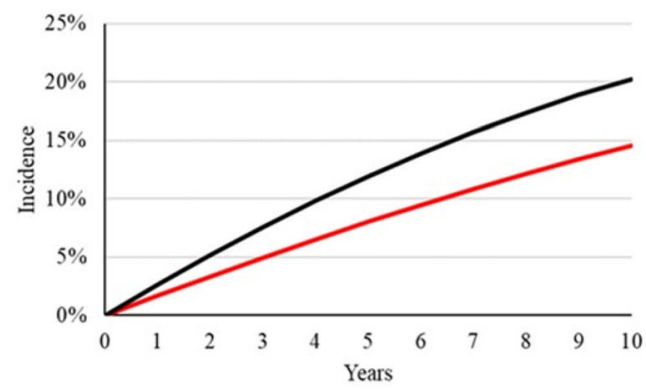

B Kidney Transplant

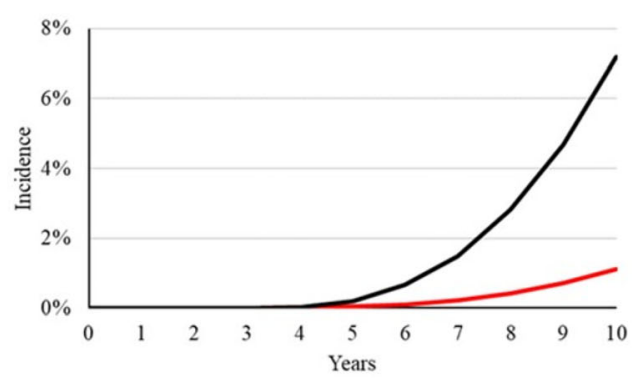

D Nonfatal Stroke

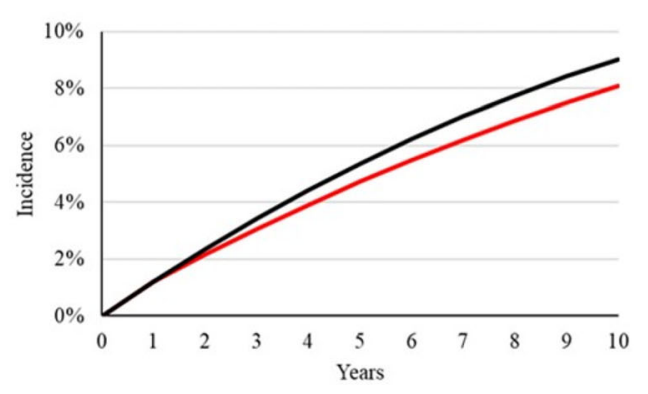

F Survival

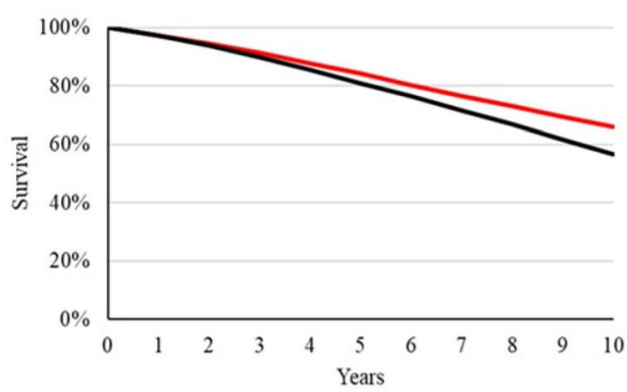

Canagliflozin $100 \mathrm{mg}+\mathrm{SoC} \longrightarrow \mathrm{SoC}$

Fig. 3 Cumulative incidence of renal and CV outcomes, by study arm. HHF hospitalization for heart failure, MI myocardial infarction

maximal tolerated dose of a RAAS inhibitor, canagliflozin $100 \mathrm{mg}$ resulted in improved survival and QALYs at substantially lower total cost, even over the relatively short 10-year time horizons chosen to limit model uncertainty associated with extrapolating far into the future. Increasing the time horizon in sensitivity analysis increased the health gains and cost savings. Uncertainty analysis suggests the results are robust.
Naturally, the most impactful parameters concerned assumptions about treatment effects. While there is no evidence suggesting that the treatment effects of canagliflozin decline over time, neither is there evidence that the benefits extend beyond the longest trial evidence thus far collected, about 6 years (i.e. CANVAS $[25,39])$. Sensitivity analysis in which CREDENCE HRs wane linearly from year 6 to year 10 had only a modest effect on the results, with canagliflozin remaining dominant 


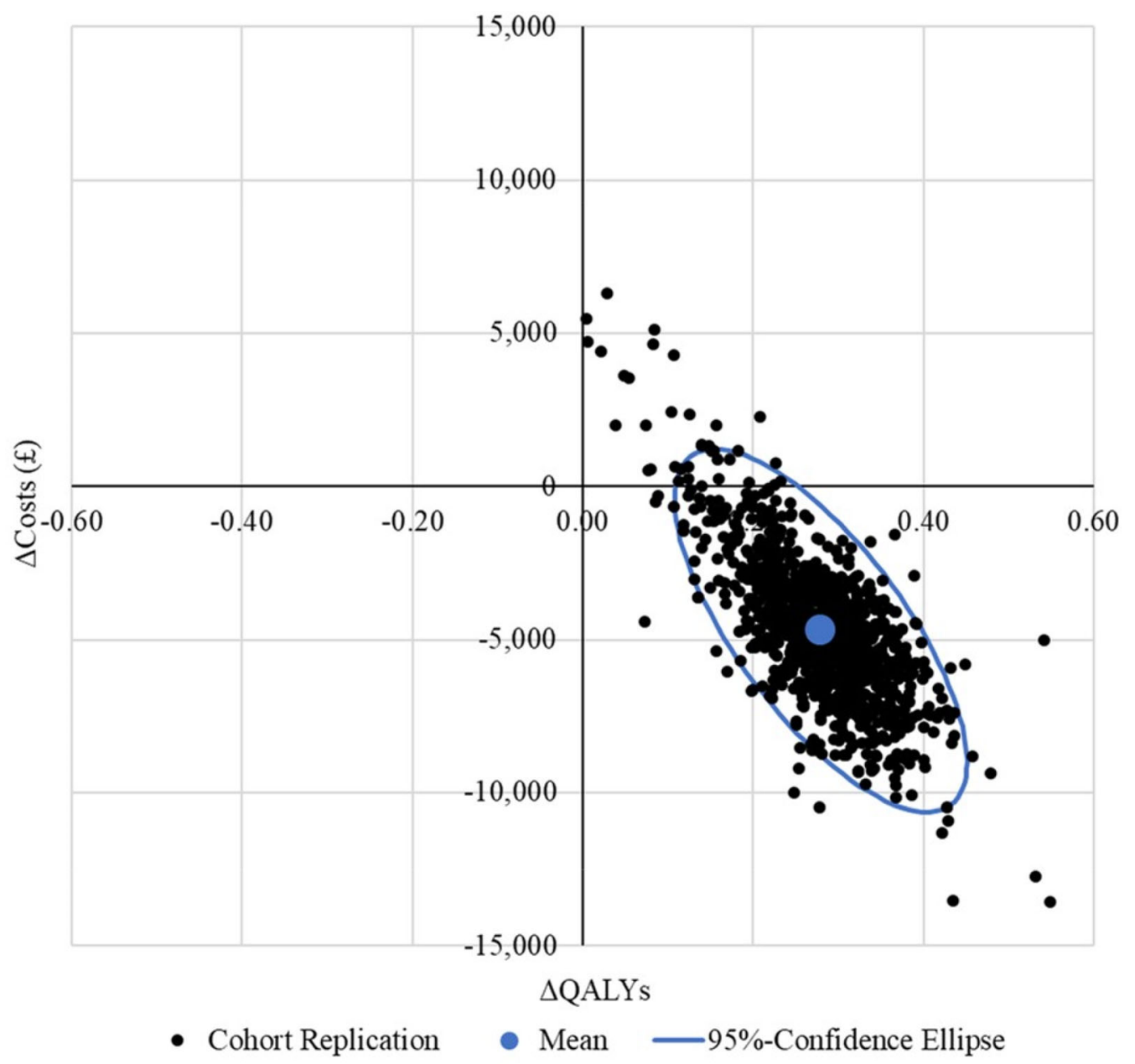

Fig. 4 Cost-effectiveness scatter plot of canagliflozin $100 \mathrm{mg}+$ SoC versus SoC alone

but with slightly reduced cost-offsets. A considerably more conservative sensitivity analysis which ignored well-established canagliflozin benefits in eGFR evolution (see Fig. 2 in Neuen et al. [39]) found that cost savings acceded to an ICER, but that this intentionally cautious ICER of $£ 20,921$ remained below the upper limit of the willingness-to-pay threshold of $£ 30,000$ per QALY gained typically used by NICE in England.

Strengths of the analysis include use of the best available evidence to date, preserving the evidence generated in the CREDENCE renal outcomes trial, and using a parsimonious and internally validated model designed for this express purpose with intentional avoidance of overfitting. Unlike other DKD models, the whole spectrum of the disease (using granular NKF/KDOQI stages), dialysis, kidney transplant, and key CV events are modelled [40]. An extensive literature review was performed to inform the QALY disutility weights for DKD (by stage) and the weights used in this study may be an improvement over previous studies [24].

Like most modeling studies, a potential weakness is the extrapolation of short-term clinical trial results to longer time horizons, though we intentionally limited the base case analysis to 10 years to reduce the amount of uncertainty that it incurred for longer time horizons. Given high mortality in this patient population, however, the effects are self-limiting. CREDENCE was stopped early because prespecified efficacy criteria had been met; had the 


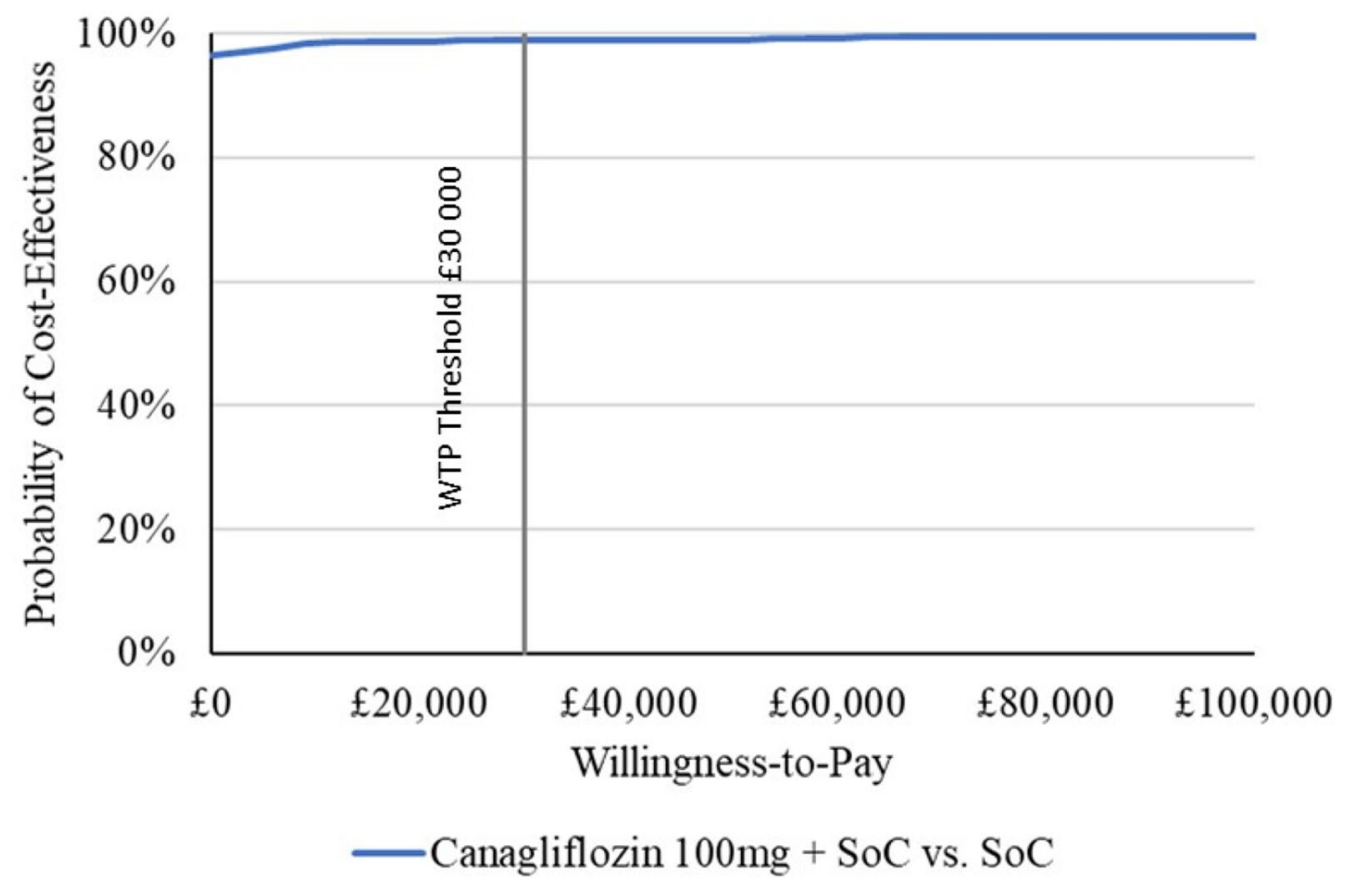

Fig. 5 Cost-effectiveness acceptability curve of canagliflozin $100 \mathrm{mg}+\mathrm{SoC}$ versus SoC alone

trial continued to full completion it is possible that risk equations for kidney transplant and 2nd CV events could have been developed, which would have further reduced decisionmaking uncertainty and their inclusion would have presumably increased between-arm separation (given that 2 nd events are conditioned on 1st events). The data to externally validate CREDEM-DKD against other renal outcomes trial are not yet available. External validation of model predictions for the $\mathrm{CV}$ outcomes and ACM against the subgroup of 567 patients in the CANVAS Program that met CREDENCE eligibility criteria matched closely for nonfatal MI and HHF, and were reasonably close for the less stable nonfatal stroke and ACM outcomes, providing additional confidence that model predictive accuracy is acceptable [19]. It should also be noted that the risk equations in the model (except kidney transplant) were derived from the multinational CREDENCE trial. Accordingly, there may be differences between improvements in renal outcomes predicted by the model and those observed in clinical practice. Nevertheless, given that NHS patients are not always treated with 'optimal' SoC, unlike in the CREDENCE trial, model outcomes may be conservative. As this analysis has been performed from the English NHS perspective, on the other hand, findings may not be directly applicable to other treatment settings.

\section{CONCLUSION}

Model-based extrapolation of the renal and cardiovascular benefits demonstrated in the CREDENCE trial to 10 years suggests that canagliflozin, used as adjunct to SoC with maximal tolerated doses of a RAAS inhibitor, can substantially reduce rates of renal and cardiovascular outcomes, and increase longevity and QALYs versus SoC alone in this high unmet need population in England, while managing to reduce total costs in the process. 


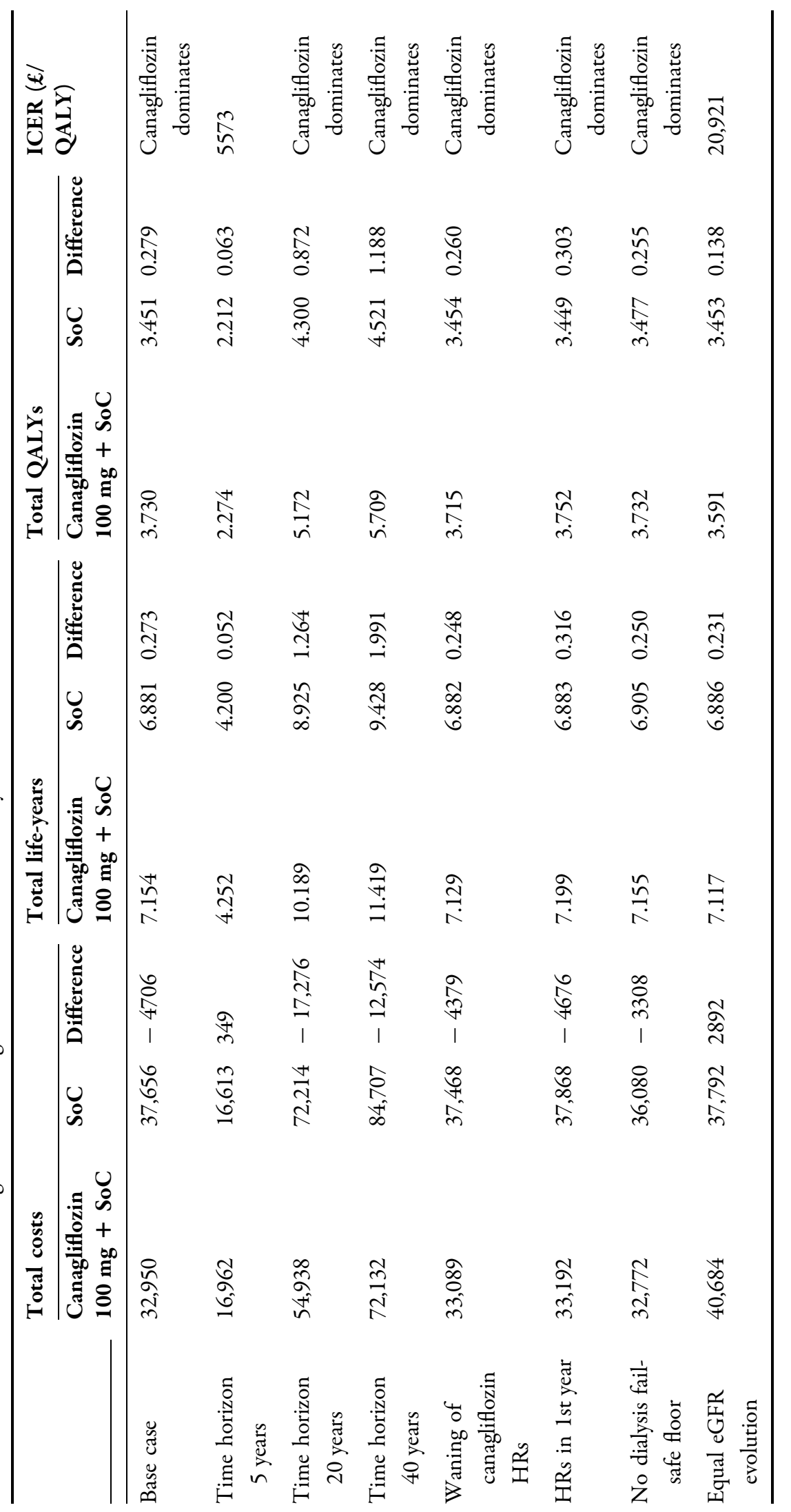




\section{A Total Costs}

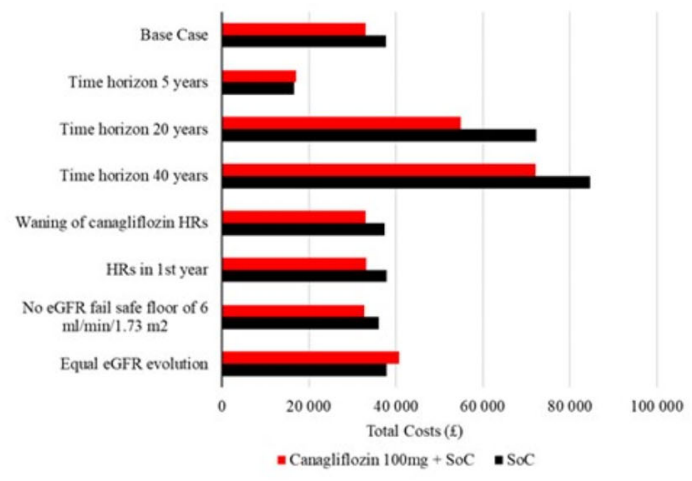

B Total QALYs

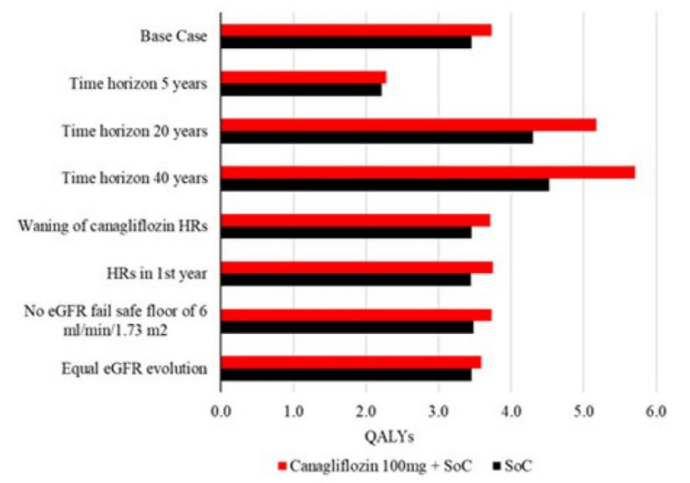

C Net Monetary Benefits*

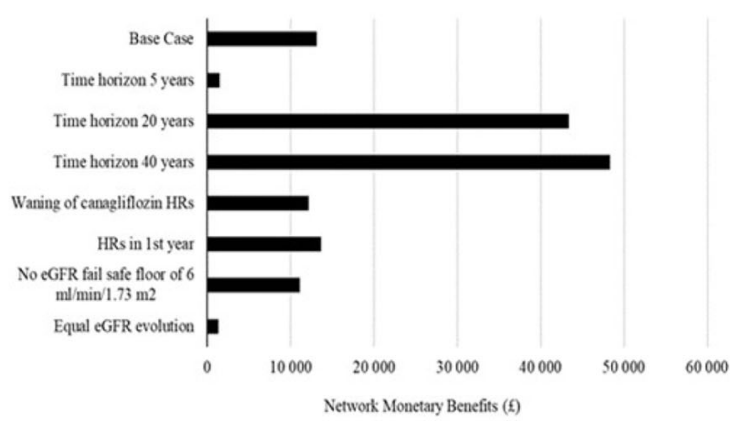

Fig. 6 Estimated total costs, total QALYs, and NMBs, by scenario. ${ }^{*}$ Willingness-to-pay of $£ 30,000$ per QALY. eGFR estimated glomerular filtration rate, HR hazard ratio, NMB net monetary benefit, QALY quality adjusted life-years

\section{ACKNOWLEDGEMENTS}

Funding. This study was financed by Mundipharma and the fees for the journal's Rapid Service were supported by Napp Pharmaceuticals Limited, part of the Mundipharma Network of Independent Associated Companies.

Authorship. All named authors meet the International Committee of Medical Journal Editors (ICMJE) criteria for authorship for this article, take responsibility for the integrity of the work as a whole, and have given their approval for this version to be published.

Disclosures. Michael Willis, Andreas Nilsson, and Klas Kellerborg are employees of the Swedish Institute for Health Economics, which provides consulting services for governmental bodies, academic institutions, and commercial life science enterprises (including Mundipharma). Michael Willis is also a minority owner and board member of the Swedish Institute for Health Economics. Philip Ball is an employee of Mundibiopharma Limited, the funding organization for this study. Rupert Roe is an employee of Napp Pharmaceuticals Limited, part of the Mundipharma Network of Independent Associated Companies. Shana Traina is an employee of Janssen Global Services, the Marketing Authorisation Holder for canagliflozin $100 \mathrm{mg}$ in Europe. Rebecca Beale and Isabelle Newell are employees of Costello Medical Consulting Limited, which provided consulting services for this study.

Compliance with Ethics Guidelines. This article is based on previously conducted studies and does not contain any studies with human participants or animals performed by any of the authors.

Data Availability. All model inputs used in this study are described or included in this article and the electronic supplementary material. The economic model used in this study is proprietary intellectual property. For access, please contact Michael Willis (mw@ihe.se). 
Open Access. This article is licensed under a Creative Commons Attribution-NonCommercial 4.0 International License, which permits any non-commercial use, sharing, adaptation, distribution and reproduction in any medium or format, as long as you give appropriate credit to the original author(s) and the source, provide a link to the Creative Commons licence, and indicate if changes were made. The images or other third party material in this article are included in the article's Creative Commons licence, unless indicated otherwise in a credit line to the material. If material is not included in the article's Creative Commons licence and your intended use is not permitted by statutory regulation or exceeds the permitted use, you will need to obtain permission directly from the copyright holder. To view a copy of this licence, visit http://creativecommons.org/licenses/by$\mathrm{nc} / 4.0 /$.

\section{REFERENCES}

1. Kerr M, Bray B, Medcalf J, O'Donoghue DJ, Matthews B. Estimating the financial cost of chronic kidney disease to the NHS in England. Nephrol Dial Transplant. 2012;27(3):73-80.

2. UK Renal Registry. 21st Annual Report-data to 31/12/2017, Bristol, UK 2019. https://www. renalreg.org/wp-content/uploads/2019/05/21st_ UKRR_Annual_Report.pdf. Accessed 23 Nov 2020.

3. Gorodetskaya I, Zenios S, McCulloch CE, et al. Health-related quality of life and estimates of utility in chronic kidney disease. Kidney Int. 2005;68(6): 2801-8.

4. Pagels AA, Soderkvist BK, Medin C, Hylander B, Heiwe S. Health-related quality of life in different stages of chronic kidney disease and at initiation of dialysis treatment. Health Qual Life Outcomes. 2012;10:71.

5. Kidney Disease Improving Global Outcomes (KDIGO). KDIGO 2012 clinical practice guideline for the evaluation and management of chronic kidney disease. Kidney Int. 2013;3(1):1-150.

6. Retnakaran R, Cull CA, Thorne KI, Adler AI, Holman RR. Risk factors for renal dysfunction in type 2 diabetes: U.K. Prospective Diabetes Study 74. Diabetes. 2006;55(6):1832-9.
7. Hill CJ, Cardwell CR, Patterson CC, et al. Chronic kidney disease and diabetes in the National Health Service: a cross-sectional survey of the U.K. National Diabetes Audit. Diabet Med. 2014;31(4): 448-54.

8. van der Velde $\mathrm{M}$, Matsushita $\mathrm{K}$, Coresh $\mathrm{J}$, et al. Lower estimated glomerular filtration rate and higher albuminuria are associated with all-cause and cardiovascular mortality. A collaborative metaanalysis of high-risk population cohorts. Kidney Int. 2011;79(12):1341-52.

9. Lavery LA, Hunt NA, Ndip A, Lavery DC, Van Houtum W, Boulton AJ. Impact of chronic kidney disease on survival after amputation in individuals with diabetes. Diabetes Care. 2010;33(11):2365-9.

10. Dalrymple LS, Katz R, Kestenbaum B, et al. Chronic kidney disease and the risk of end-stage renal disease versus death. J Gen Intern Med. 2011;26(4): 379-85.

11. Perkovic V, Jardine MJ, Neal B, et al. Canagliflozin and renal outcomes in type 2 diabetes and nephropathy. N Engl J Med. 2019;380(24): 2295-306.

12. Brenner BM, Cooper ME, de Zeeuw D, et al. Effects of losartan on renal and cardiovascular outcomes in patients with type 2 diabetes and nephropathy. N Engl J Med. 2001;345(12):861-9.

13. Lewis EJ, Hunsicker LG, Clarke WR, et al. Renoprotective effect of the angiotensin-receptor antagonist irbesartan in patients with nephropathy due to type 2 diabetes. N Engl J Med. 2001;345(12): 851-60.

14. European Medicines Agency. Invokana-summary of opinion (post authorisation). 2020. https://www. ema.europa.eu/en/documents/smop/chmp-postauthorisation-summary-positive-opinion-invokanaii-46_en.pdf. Accessed 9 July 2020.

15. Drummond M, Sculpher M, Torrance G, $\mathrm{O}^{\prime}$ Brien B, Stoddart G. Methods for the economic evaluation of health care programmes. 3rd ed. Oxford: Oxford University Press; 2005.

16. Farahani P. A perspective on principles of comparative cost-effectiveness studies for pharmacotherapy of chronic diseases. Clin Diabetes. 2012;30(2): 54.

17. Weinstein MC, O'Brien B, Hornberger J, et al. Principles of good practice for decision analytic modeling in health-care evaluation: report of the ISPOR Task Force on Good Research PracticesModeling Studies. Value Health. 2003;6(1):9-17. 
18. Briggs A, Claxton K, Sculpher M. Decision modelling for health economic evaluation (handbooks in health economic evaluation). 1st ed. Oxford: Oxford University Press; 2006.

19. Willis M, Asseburg C, Slee A, Nilsson A, Neslusan C. Development and internal validation of a discrete event simulation model of diabetic kidney disease using CREDENCE trial data. Diabetes Ther. 2020;11(11):2657-76.

20. Mahaffey KW, Jardine MJ, Bompoint S, et al. Canagliflozin and cardiovascular and renal outcomes in type 2 diabetes and chronic kidney disease in primary and secondary cardiovascular prevention groups: results from the randomized CREDENCE trial. Circulation. 2019;140:739-50.

21. Roberts M, Russell LB, Paltiel AD, Chambers M, McEwan P, Krahn M. Conceptualizing a model: a report of the ISPOR-SMDM modeling good research practices task force-2. Med Decis Making . 2012;32(5):678-89.

22. National Kidney Foundation. 2018. https://www. kidney.org/professionals/guidelines/guidelines_ commentaries. Accessed 5 May 2020.

23. National Kidney Foundation. K/DOQI clinical practice guidelines for chronic kidney disease: evaluation, classification, and stratification. Am J Kidney Dis. 2002;39(2 Suppl 1):S1-266.

24. National Institute for Health and Care Excellence. Single technology appraisal (STA)-Tolvaptan for treating autosomal dominant polycystic kidney disease (TA358) Manufacturer Submission. 2012.

25. Neal B, Perkovic V, Mahaffey KW, et al. Canagliflozin and cardiovascular and renal events in type 2 diabetes. N Engl J Med. 2017;377(7):644-57.

26. Vemer P, Corro Ramos I, van Voorn GA, Al MJ, Feenstra TL. AdViSHE: a validation-assessment tool of health-economic models for decision makers and model users. Pharmacoeconomics. 2016;34(4): 349-61.

27. NHS Business Services Authority. https://applications. nhsbsa.nhs.uk/DMDBrowser/DMDBrowser.do. Accessed 27 July 2020.

28. Tattersall J, Dekker F, Heimbürger O, et al. When to start dialysis: updated guidance following publication of the Initiating Dialysis Early and Late (IDEAL) study. Nephrol Dial Transplant. 2011;26(7):2082-6.

29. UK Renal Registry. 2019. UK Renal Registry 21st Annual Report—data to 31/12/2017, Bristol, UK. https://www.renalreg.org/publications-reports/.
30. Alva ML, Gray A, Mihaylova B, Leal J, Holman RR. The impact of diabetes-related complications on healthcare costs: new results from the UKPDS (UKPDS 84). Diabetic Med. 2015;32(4):459-66.

31. Jesky MD, Dutton M, Dasgupta I, et al. Health-related quality of life impacts mortality but not progression to end-stage renal disease in pre-dialysis chronic kidney disease: a prospective observational study. PLoS One. 2016;11(11):e0165675.

32. Lee AJ, Morgan CL, Conway P, Currie CJ. Characterisation and comparison of health-related quality of life for patients with renal failure. Curr Med Res Opin. $2005 ; 21(11): 1777-83$.

33. Clarke P, Gray A, Holman R. Estimating utility values for health states of type 2 diabetic patients using the EQ-5D (UKPDS 62). Med Decis Making. 2002;22(4):340-9.

34. NICE. Canagliflozin, dapagliflozin and empagliflozin monotherapy for treating type 2 diabetesAssessment Report National Institute for Health and Care Excellence. 2015.

35. Shingler S, Fordham B, Evans M, et al. Utilities for treatment-related adverse events in type 2 diabetes. J Med Econ. 2015;18(1):45-55.

36. NHS Improvement. Reference Cost Collection: National Schedule of Reference Costs, 2018-19. NHS trusts and NHS foundation trusts. 2019. https://improvement.nhs.uk/resources/referencecosts/.

37. Peasgood T, Brennan A, Mansell P, Elliott J, Basarir $\mathrm{H}$, Kruger J. The impact of diabetes-related complications on preference-based measures of healthrelated quality of life in adults with type I diabetes. Med Decis Making. 2016;36(8):1020-33.

38. Sullivan PW, Ghushchyan VH. EQ-5D scores for diabetes-related comorbidities. Value Health . 2016;19(8):1002-8.

39. Neuen BL, Ohkuma T, Neal B, et al. Effect of canagliflozin on renal and cardiovascular outcomes across different levels of albuminuria: data from the CANVAS program. J Am Soc Nephrol. 2019;30: 2229-42.

40. Sugrue DM, Ward T, Rai S, McEwan P, van Haalen HGM. Economic modelling of chronic kidney disease: a systematic literature review to inform conceptual model design. Pharmacoeconomics. 2019;37:1451-68. 